\title{
CONSUMERISM INDEX IN THE CONTEXT OF SUSTAINABLE DEVELOPMENT: PATTERN OF HOUSEHOLD FOOD CONSUMPTION
}

\author{
FRANCISIA S.S.E SEDA*, LUGINA SETYAWATI, TIMOTI TIRTA, KEVIN NOBEL \\ KURNIAWAN AND PEBRIANSYAH
}

Department of Sociology, Faculty of Political and Social Science, University of Indonesia.

*Corresponding author: ery.seda09@ui.ac.id

Submitted final draft: 29 May 2020 Accepted:8 June $2020 \quad$ http://doi.org/10.46754/jssm.2021.06.021

\begin{abstract}
This study focuses on the phenomenon of consumerism as a component of sustainable development. Sustainable development assumes the balance of production and consumption in the economy. The notion of consumption is framed to be a balanced and sustainable approach by considering the economic, social, and cultural aspects of food consumption. This multidimension aspect of food consumption incorporates other forms of non-economic principles in lubricating and prolonging its economic sustainability. This research focuses on the city of Bandung, a major Indonesian urban area that contributes to the national economy, and also one that maintains traditional norms that constitutes the multidimensional dynamic of food consumption. The testing and measurements of the consumerism index are done through a random sampling survey of 150 respondents distributed in two districts, with a confidence interval of $92.7 \%$. This research shows that advertisement and distribution of global food products, together with the participation of friends and families in consuming food, tend to be more influential in causing stronger behaviour of food consumption. This confirms the novelty of this research that the multidimensionality of consumption remains relevant, thus a consumerism index based on the variety of aspects are recommended for future development in the study of sustainability and consumption.
\end{abstract}

Keywords: Consumerism Index; Cultural Dimension; Economic Dimension; Social Dimension; Sustainable Development.
Abbreviation
$C R \quad$ Construct reliability
E10 The frequency of buying food products online
E11 Having a preference to purchase online food products or food service
E15 Having a preference to a specific brand in the purchase of staple foods
E17 The frequency of eating outside the home/ in a restaurant with family
E18 The frequency of ordering Saver packages when eating in a restaurant
E19 Eating outside/in a restaurant that provides discounts as a preference
E22 The frequency of eating in a restaurant that is giving discounts
E27 Price to be considered in the purchase of rice
E28 Price to be considered in the purchase of oil
E29 Price to be considered in the purchase of sugar
E8 The frequency of eating outside the home/in a restaurant
EINS Economic-institutional component 
EKO Economy variable

ENIL Economic-value component

EPRA Economic-practical component

GOFI Goodness of fit index

K13 whether traditional restaurants are a preference in the activities of eating out with the family

K14 the preference for traditional dishes in the activities of eating out with the family

K18 the frequency of serving varied dishes in the daily menu for the consumption of the family

K20 the frequency of serving the composition of rice, side dish, vegetables, fruits in the daily diet

K21 The frequency of presenting dishes that meet the nutritional balance

K3 On Religious Principles/values as a consideration in family consumption

K4 Halal principle for processed foods as a major consideration in family consumption

K5 About the halal principle for processed foods as major consideration in family consumption

KINS Cultural-institutional component

KNIL Cultural-value component

KPRA Cultural-practical component

KUL Cultural variable

S12 The frequency of watching culinary programs on TV

S13 The frequency of practicing recipes obtained from culinary programs on TV

S15 The frequency of consumption of food products advertised on TV

S17 The frequency of using recipes from the social media

S19 The frequency of using recipes from friends

$S 2 \quad$ The selection of food to create an image of the family's socioeconomic status

S21 Consuming food based on the advice of culinary figures

$S 24 \quad$ Brand is the main consideration in buying rice

S25 Brand is the main consideration in buying oil

S26 Brand is the main consideration in buying sugar

S8 The frequency of following the latest culinary information

SINS Social-institutional component

SLF Standardized loading factor

SNIL Social-value component

SOS Social variable

SPRA Social-practical component

$V E \quad$ Variance extracted 


\section{Introduction}

This study focuses on the phenomenon of consumerism in urban society in the context of sustainable development (Assadourian, 2010; Sebastien and Bauler, 2013). Sustainable development is the capacity of resource distribution to promote a long-term usage of goods in ensuring a higher quality of life, while maintaining cultural and local characteristics, and a balanced form of production and consumption (Brown \& Vergragt, 2015; Klarin, 2018; Otero et al., 2018; UN, 2015). Specifically, in this study, it would like to be pointed out that not only sustainable development responds to the basic needs of consumers, but also to cultural needs. In fact, it is by responding to such noneconomical aspect of production-consumption relation that it is capable of maintaining and supporting a balanced and stronger form of economic relations.

Food consumption is a form of economic consumption and has become the fundamental element of national sustainable development. In this era, the consumer society participates in global capitalism based on their basic needs, cultural characteristics, and life orientation (Dalgliesh, 2014; Bauman, 2005; Wahyudi et al., 2019). By understanding the dynamics of post-Fordism manifested in the phenomenon of consumerism in Indonesia, it is perhaps appropriate to understand the dynamics of the domestic economy. By doing so, one would be able to provide input for governmental policies to correspond to the level of consumerism in society in the context of sustainable development (Virno, 2007; Jain, 2016). On a certain manner of perspective, this research may not have a direct impact on the efforts to safeguard national economic resilience in the global economy, but it is the novel preliminary step towards a wider national economic resilience and the context of sustainable development through a multidimensional analysis of food consumption (Dalgliesh, 2014; Simmie \& Martin, 2010).

Consumption is a core determinant of national economic resilience and sustainability. While various factors have contributed to the formation of economic resilience and sustainable development, including governmental policies and circulation of capital, one often omit the micro-aspect of consuming food, consumers' preferences, and food purchases as a dominant element in building economic growth. (Bashir \& Yuliana, 2018; Kurniawan \& Managi, 2018; O'Cass \& Mcewen, 2004; Seda et al., 2013; Taiss, 2012). And if one would further proceed to extend its influence to the global economy, we might understand that daily food consumption can affect the national economy, and later becoming the foreground to which national economic resilience is made to withstand the international flow of capital (Trentmann, 2004; Robinson, 2011). In other words, the lifestyle of a country's domestic population contributes to the state's economic position within the global world (Amin, 1994; Robinson, 2011; Lazzarato, 2004). The operations of a variety of media and institutions, such as mass media, television, social media, and open markets, further enhances the practice of food consumption in society (Ageev \& Ageeva, 2015; Bergman, 2018; Lazzarato, 2007; Rukmana, 2008; Stellarosa \& Ikhsano, 2015).

The aim of this research is to contribute to new knowledge on urban food consumption, which can be used as a measure of economic sustainability. With the application of social, economic, and cultural dimensions in the analysis, it is hoped that the multidimensional analysis can be a valid and proper measurement to indicate the variety of food consumption forms in Indonesia and other countries.

\section{The Multidimensional Aspect of Food Consumption}

Food consumption is understood as an activity that mainly involves the purchasing and consuming of food. While the act of consumption itself is often considered as a "normal" or mundane practice in everyday social situation, various forms of economic price modifications, institutional influence of media advertisement, and the cultural character of its consumers further enhances the practice of consumption, 
making it an act of consumerism. A balanced and multidimensional form of consumerism, that not only meets basic needs, but also the expression of socio-cultural orientation of societal life, will be able to contribute to the national economy. (Barbopoulos \& Johansson, 2016; Kurenlahti \& Salonen, 2018; Firat et al., 2013).

Food consumption patterns are influenced by three dimensions of consumerism. First, the cultural dimension that explains the traditional elements that affect the activity of consuming food by individuals/households; second, the economic dimension that explains the instrumental-rational elements that influence the activity of consuming food by individuals/ households; and, third, the social dimension that explains the influence of social interactions that influence the activity of consuming food by individuals/households (Bossy, 2014; Eryandra, 2018; Ikran, 2009; Shukla, 2010). These three dimensions hold an interplay that encourages the consumer to purchase and consume food. Consumption is not only confined within the specific phenomenon of economic uses, it also involves social and cultural realities (Nicolau et al., 2009).
By referring to a previous study on Consumerism Indicators in Jakarta in 2013, this study attempts to reapply the multidimensional framework into the city of Bandung (Seda et al., 2013). It has already been argued that the multidimensional aspects of consumerism are important. However, it should be noted that there are also "sub-dimensions" or further minor indicators, which shows the varying compositions of the major aspects of consumerism: Practical indicator, Price indicator, and Institutional indicator (Chen et al., 2017; Huang et al., 2017; Rohani et al., 2012; Kurenlahti et al., 2018; Victor et al., 2018). For example, the cultural aspect of food consumption due to religious principles also involve the price of food, the institutional influence of advertisement, and the consumer's everyday habit of food consumption. Let us consider the dimensions of consumerism as the behaviour as a "more fixed" form of food consumption (second order variables), while the subdimensions of consumerism as the casual or quick preference towards food products (first order variables). The framework of this study's analytical roadmap is visually illustrated in Figure 1 below:

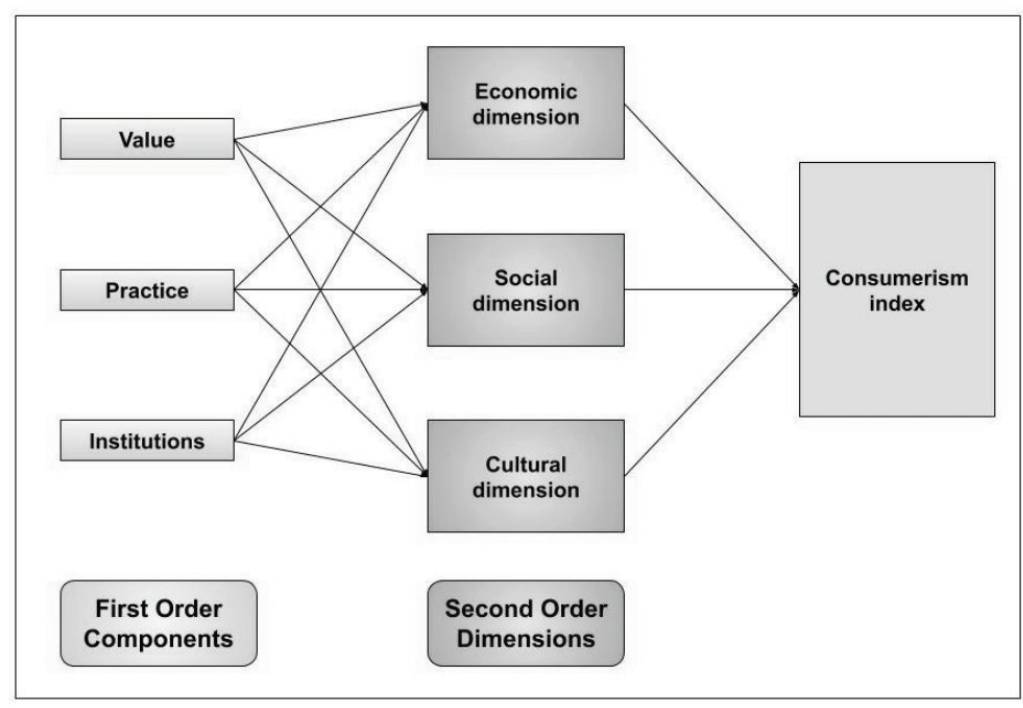

Figure 1: The research framework 


\section{Methodology}

This research focuses on the urban city of Bandung. The high level of domestic demand in Bandung as an urban area attracts investors to circulate their capital domestically (Astuti et al., 2010; Dinh et al., 2019). It is to be noted that high domestic consumption is only made possible by the phenomenon of consumerism in society (Migone, 2006). To understand the phenomenon of consumerism in the Indonesian society, a sociological analysis cannot be separated from the features of post-Fordist capitalism, that is primarily described as consumption as an interaction between domestic and global capitalism (Lazzarato, 2009; Tauss, 2012; Jha \& Chakraborty, 2014). This research is based on primary quantitative data that has been collected, tested, and measured within the years 2015 to 2016 .

To understand the characteristics and fundamentals of the national economy, it is necessary to know the characteristics of the domestic economy at the household level. The heterogeneous nature and condition of the Indonesian society based on the geographical area, socio-economic strata, and culture require a comprehensive perspective in studying the dynamics of the domestic economy that marks the characteristics of the community. The characteristics of the Indonesian society, consisting of urban and rural communities, manifest the importance of the dimensions of consumerism used to observe the unique economic characteristics and distinguish between the two regions.

The importance of focusing on the urban and rural regions are to be highlighted. The urban community of Bandung in West Java is selected due to it being a middle-sized urban area, with a high concentration of young urban population famed for its local tradition, and has a basic food consumption pattern that is based on both metropolitan and traditional mix of economic exchanges (Rahadi et al., 2017; Prayudi et al., 2017). Therefore, this study tries to construct a consumerism index with the initial goal of creating an understanding of the dynamics of consumerism itself. In Indonesia, the novelty of the consumerism index, as proposed in this research, will contribute to the study of sustainable development based on economic, social, and cultural dimensions. In accordance to the purpose of research, in the measurement of the consumption index, the study uses the following methods for data collection:

\section{Survey \& Sampling}

This technique is the primary method of collecting data to measure the food consumption at the household level in urban areas. The observation unit of the survey is the mother or wife of the household, who lives at Bandung for at least five year. This determination is based on the typical Indonesian family, in which the mother/wife plays a vital role in the management of a family's food consumption.

First, it is to take a random sample in neighbouring districts, this study selected two out of 29 districts in Bandung. Second, within the framework of two districts, we set a random sampling frame of 150 respondents, based on the Slovin formula, to represent 784 households in the two selected districts; each respondent representing a household. In the process of selection, we have put into a consideration of having a $7.3 \%$ sampling error; Third, is to further do a random sampling selection to choose 150 respondents from among the 784 households, deriving from both primary and substitutionary respondents; Fourth, taking part in a face-toface interview to fill in a questionnaire.

\section{Observation}

The observation method is, in principle, applied to complement the survey. The observation is carried out in the environment of the study locations, including the existence of facilities, use of the public/citizen areas of facilities and the available access to food needs and consumption patterns of citizens and families who participate in the study through surveys. The observation happened throughout the field research process. 


\section{Structural Equation Modeling Analysis}

Structural Equation Modeling (SEM) analysis was used as it can capture the simultaneous correlation of differing variables that affects consumerism as the primary focus in this research. Not only that it provides an explanatory framework on how the variables are related, but it also confirms their correlations. The results of the measurement model includes a test on Standardized Loading Factor (SLF) and the reliability of the instrument as calculated in the Construct Reliability (CR) and Variance Extracted (VE) performed for all study variables, consisting of three-second order latent variables, i.e., ECONOMY (EKO), CULTURAL (KUL), and SOCIAL (SOS) (Kocakaya and Kocakaya, 2014).

As shown in Figure 1, there are two stages of analysis. The first stage measures the value of first-order components: Value, Practice and Institution. And the second stage measures the correlation between the first-order variables (Value, Practice, and Institution) and the secondorder dimensions (Economic, Social, and Cultural). The first stage of analysis determines the respondents' preference in food selection, purchase, and consumption. The second stage of analysis describes whether the respondents' preference in food selection and consumption has a significant connection to consumerism.

The first-order components are variables represented by the items in the questionnaire. The second-order dimensions of Economic dimensions are measured through the SEM analysis. There are various acronyms to describe the various aspects and "sub-aspects" of consumerism: EINS (economic-institutional component), ENIL (economic-value component), and EPRA (Economic-Practical component). The second-order dimensions KUL (cultural): KINS (cultural-institutional component), KNIL (cultural-value component), and KPRA (culturalpractical component). The last variable, SOS (social), consists of SINS (Social-Institutional component), SNIL (Social-Value component), and SPRA (Social-Practical component). The following are the results of data processing using the structural equation modeling (SEM) analysis.

The analysis for each aspects of consumerism is then carried out. The analysis on the economical aspect of consumerism is described in Figures 2, 3, 4 and 5. The analysis on the cultural aspect is described in Figures 6, 7, 8 and 9. Lastly, the analysis on the institutional aspect is described in Figures 10, 11, 12 and 13. And the overall analysis, which encompasses the general analytical framework, is described in Figure 14.

\section{Profiles of the Survey Areas}

Coblong is one of the districts of Bandung City. According to Bandung Statistics Office data, the projected number of inhabitants in this district in 2014 was 131,435. The district consists of six subdistricts: Cipaganti, Lebak Siliwangi, Lebak Gede, Sadang Serang, Sekeloa, and Dago. The total area of the six subdistricts is 743.3 ha. From observation, this area has some facilities supporting consumption patterns, such as traditional markets, shopping malls/shopping centres, retailers, etc. The second area is Sukajadi district. According to Bandung Statistics Office data, the projected number of inhabitants in this district in 2014 was 108,045. The district consists of five subdistricts: Pasteur, Cipedes, Sukabungah, Sukagalih, and Sukawarna. The total area of the five subdistricts is 430.9 ha. Similar to Coblong, there are some providers of traditional markets, shopping malls/shopping centres, retailers, and others. In Coblong district, there are 652 restaurants, 4 traditional markets providing raw food materials, and 8 modern markets selling food at higher prices.

The district of Sujakadi has 327 restaurants, a traditional market built since 1967, having around 1310 participating retail stores, and 104 modern markets. In general, both communities provide local food services from diverse cultural backgrounds (Sundanese food, Javanese food, Chinese food, and other traditional food). Both districts also have conventional and online transportation services that allow online food purchases. In terms of social stratification, it 
is found that the house distance of middle, middle-low, and low residential areas were not very far from one another - the residents tend to have a higher interaction and social meetings, encouraging communal food consumption.

\section{Results and Discussion}

This study is based on the reapplication of the multidimensional consumer index (Seda et al., 2013) The results of the measurement model are performed for all study variables, consisting of three first-order latent variables and three secondorder latent variables (Sarstedt et al., 2017). The first-order variables (Value, Practice, and Institution), which describe the consumers' food preference is first described, and then followed by an overall overview of its economic, social, and cultural aspect (second-order variable) in the process of consumerism. By reading the preference for food and later to its formation of one aspect of consumerism, the "ground-to-top" reading will be able to provide a description from the micro-aspect of food purchase to the macro-aspect of food consumerism.

\section{The Economic Dimension}

The economic dimension consists of three first-order components: economic-value, economic-practice, and economic-institutional. The variable economic-value represents the respondent's perception of the economic components related to the value component in question no. E27, E28, and E29: the price to be considered in the purchase of rice, oil, and sugar as basic commodities (Jati, 2013; LPPM, 2018). The variable of economic-practice represents the respondent's perceptions of the economic components related to the practical component in question no. E8 (the frequency of eating outside the home/in a restaurant when the price of basic commodities rise), E10 (the frequency of buying food products online), E17 (the frequency of eating outside the home or in a restaurant with family), E18 (the frequency of ordering saver packages when eating outside the home or in a restaurant) and E22 (the frequency of eating in a restaurant that is giving discounts). The variable economic-institutional represents the respondent's perception of the economic component related to the institutional component in the following questions: E11 (having a preference to purchase online food products or food service), E15 (having a preference to a specific brand in the purchase of staple foods that are processed already) and E19 (eating outside or in a restaurant that provide discounts as a preference when eating out with the family).

Figures. 2, 3, and 4 describe the respondents' preferences in purchasing food. There are two components that are significantly correlated to The Economic Dimension: the value component and institutional component, having Chisquares of 0.00 . In terms of the respondents' economic preference towards food purchase, the findings show that they have a stronger interest in the price of food items and food branding or advertisements.

Figure 5 shows that the Goodness of Fit Index of the correlation between the latent variables: economic-value component, economic-practice component, and economic institutional component. The Root Mean Square of Error of Approximation shows a value of 0.00 (lower than 0.08), showing the model fits and the Chi-square is not inflated due to a large sample (the model is saturated). It can be concluded that the data strongly support the model for latent variables economic-value component, economic-practice component, and economicinstitutional component, and the data also have good validity with a standardised loading factor value of $\geq 0.50$. Focusing on the Overall Economic Component (Figure 5), we have found that there is a significant correlation (Chi-square $=0.00)$ represented by the various components: economic-practice component and economicinstitutional component. Having the economicpractice component as a significant dimension of consumerism, with a loading factor of 1.00 (higher than 0.5). The economic-institutional component has a loading factor of only 0.75 towards the Overall Economic Variable. 


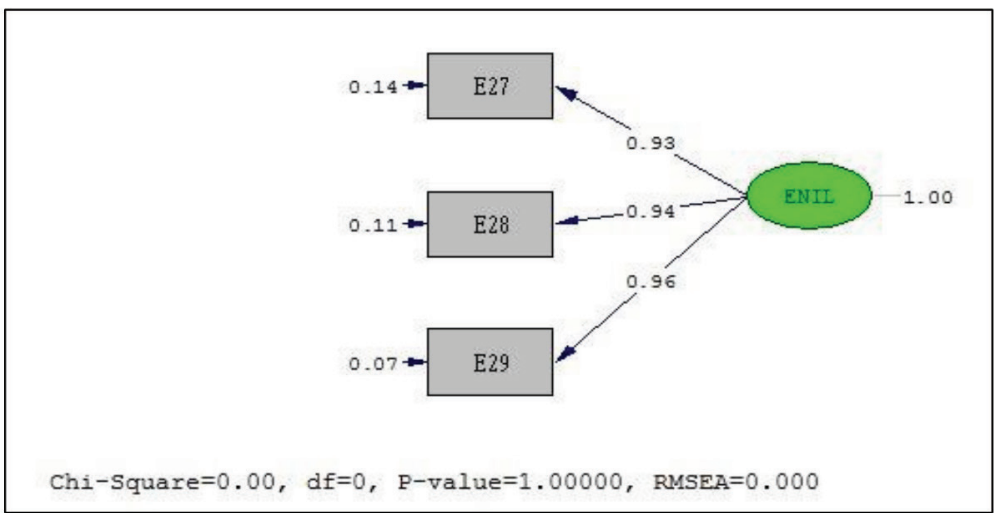

Figure 2: Data processing of the Value component of the latent variable Economy (Second-stage processing after eliminating items with standardised loading factor $<0.50$ )

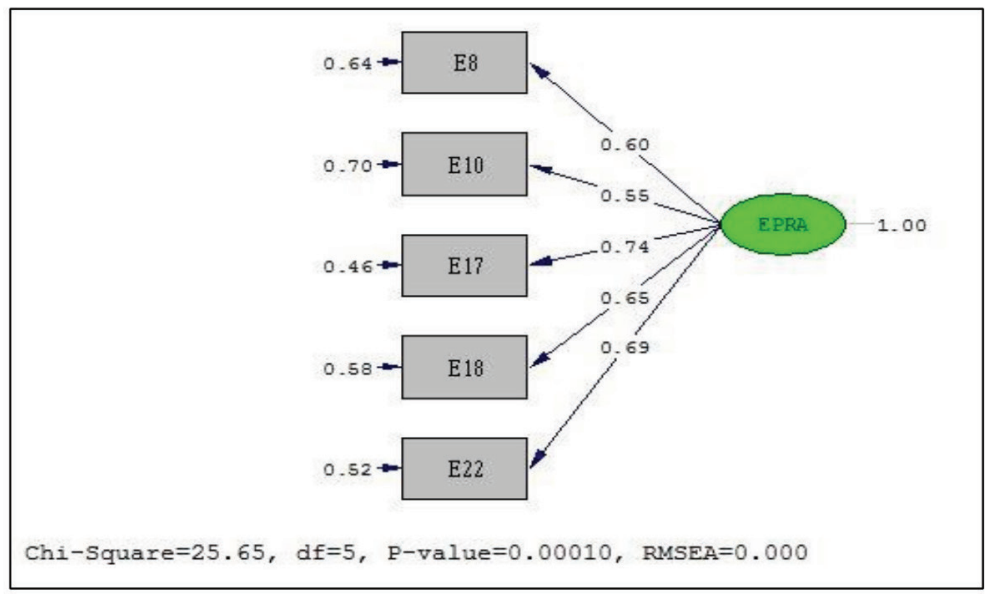

Figure 3: Data processing of the Practical component of the latent variable Economy (Second stage processing after eliminating items with standardised loading factor $<0.50$ )

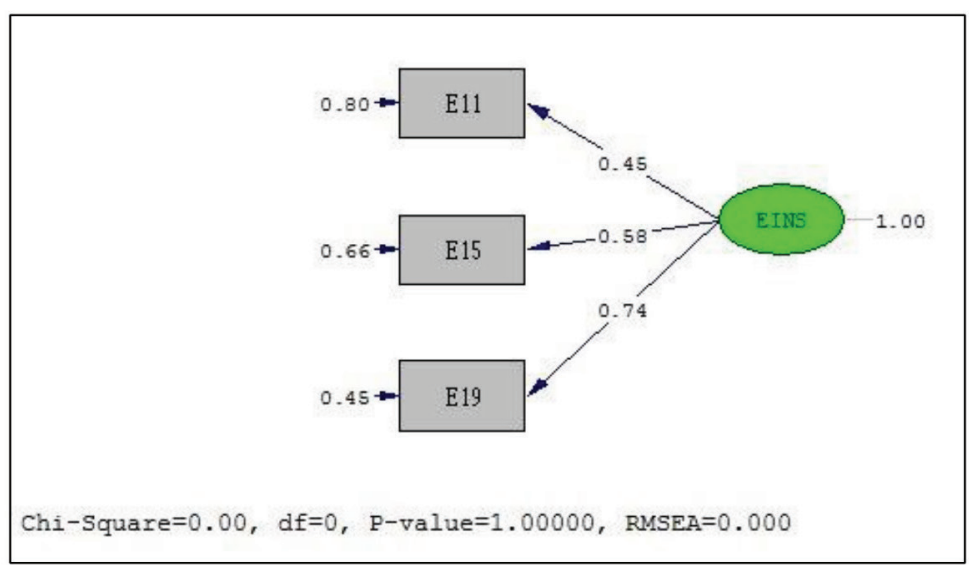

Figure 4: Data processing of the Institution component of the latent variable Economy (Second stage processing after eliminating items with standardised loading factor $<0.50$ ) 


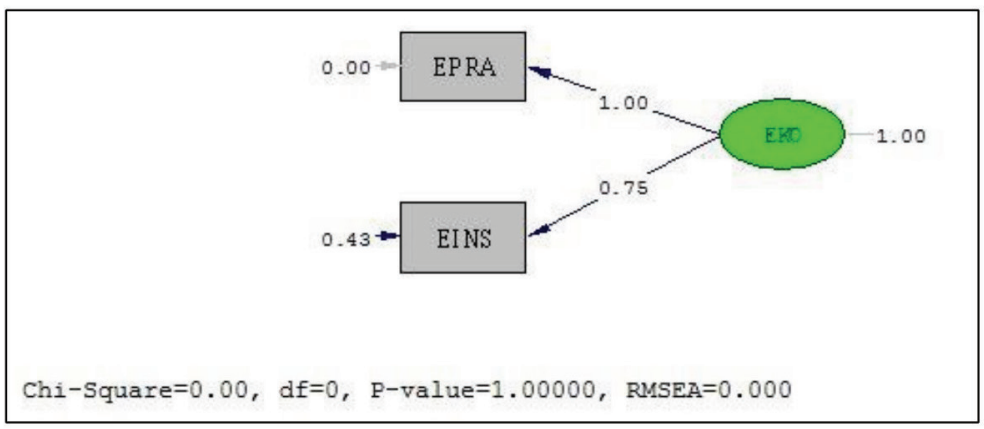

Figure 5: Data processing of the latent variable Economy

(Second stage processing after eliminating items with standardised loading factor $<0.50$ )

There is no significant correlation between the Overall Economic Component and economicvalue component. This finding shows that there is no correlation between the overall economic variable and economic-value component: respondents do not consider the price of rice, oil, and sugar as a major variable that directs towards consumerism. On the contrary, the economic dimension of consumerism is driven by the practice and institutional component: respondents are more likely to consume food in a restaurant and purchase food products through the use of internet and also to purchase food from a restaurant whenever a discount is available.

\section{The Cultural Dimension}

The second-order cultural dimension consists of three first-order components: culture as value component, culture as practical component, and culture as institutional component through the following measurement model: The variable culture as value component represents the respondent'; s perception of the cultural components related to the value component in questions no. K3 (on religious principles/values as a consideration in family consumption), $\mathrm{K} 4$, and $\mathrm{K} 5$ about the halal principle for processed foods as a major consideration in family consumption. The variable, culture, as a practical component, represents the respondent's perception of the cultural components related to the practical component in questions no. K18 (the frequency of serving varied dishes in the daily menu for the consumption of the family),
K20 (the frequency of serving the composition of rice, side dish, vegetables, fruits in the daily diet), and K21 (the frequency of presenting dishes that meet the nutritional balance). The variable, culture, as an institutional component, represents the respondent's perception of the cultural components related to the institutional component in question no. K13 (whether traditional restaurants are a preference in the activities of eating out with the family), and K14 (the preference for traditional dishes in the activities of eating out with the family).

Figures 6, 7 and 8 describe the respondents' cultural preference for food consumption. All three are significantly correlated to the Cultural Dimension: the value component, the practical component, and institutional component having chi-square scores of 0.00 . In terms of the respondents' cultural preference, the findings show that they are interested in the frequency, religious principles, and family customs, which suggest how and where food is being served and consumed. Family, local tradition, and religious principles play a significant role in determining the type of food consumed.

Based on the results of the output from the figures above, it shows that the indicator of the Goodness of Fit Index of the latent variables culture as value component, culture as practical component, and culture as institutional component. The Root Mean Square of Error of Approximation shows a value of 0.00 (lower than 0.08), showing the model fits, and the Chi-square is not inflated due to a large sample 


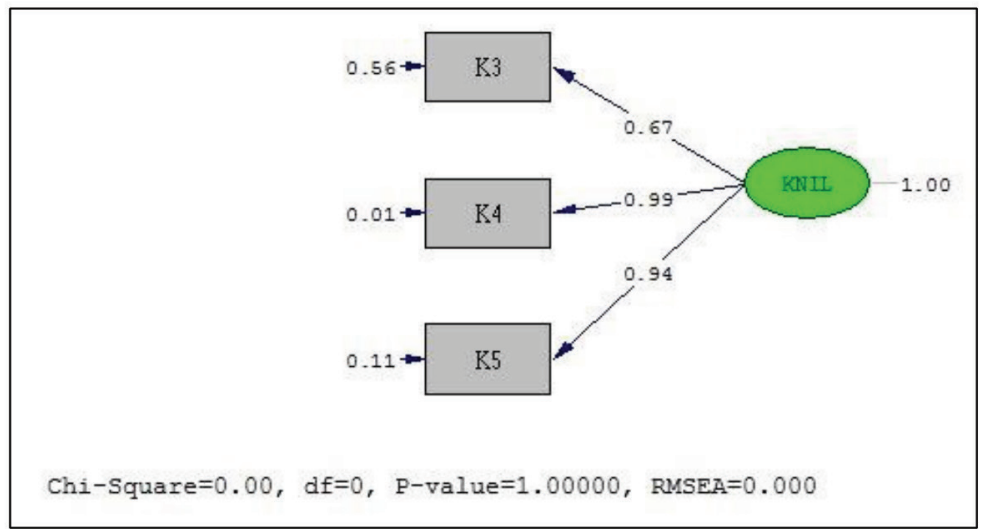

Figure 6: Data processing of the Value component of the latent variable Cultural (Second stage processing after eliminating items with standardised loading factor $<0.50$ )

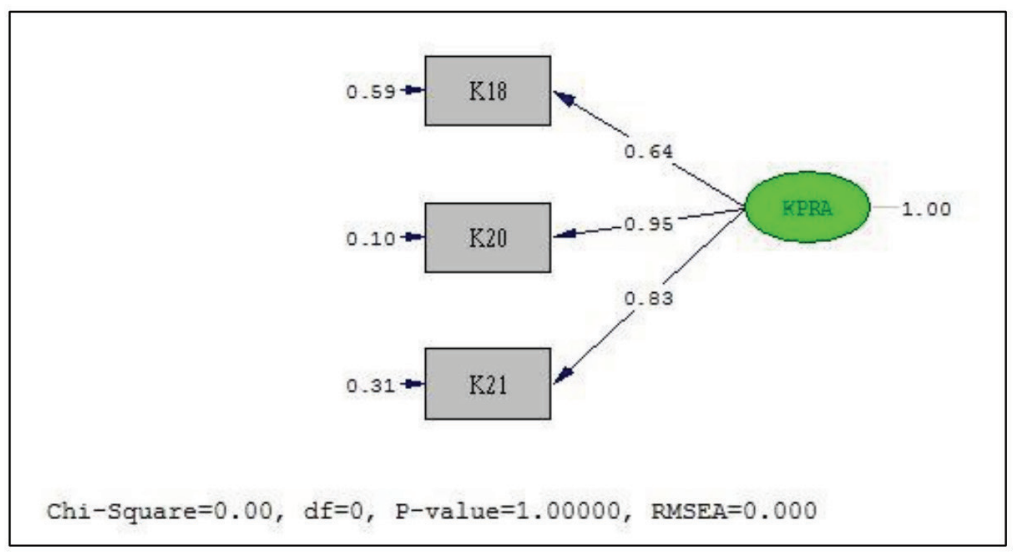

Figure 7: Data processing of the Practical component of the latent variable Cultural (Second stage processing after eliminating items with standardised loading factor $<0.50$ )

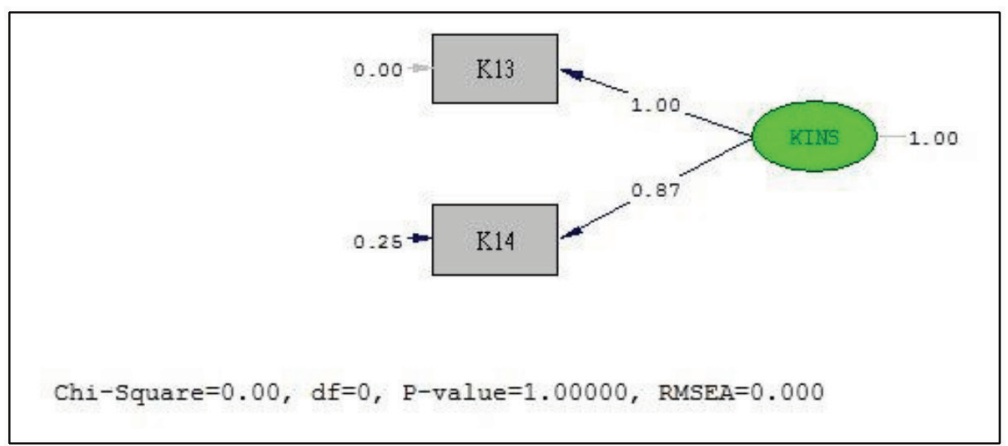

Figure 8: Data processing of the Institution component of the latent variable Cultural (Second stage processing after eliminating items with standardised loading factor $<0.50$ ) 
(The model is saturated). It can be concluded that the data strongly support the model for latent variables economic-value component, economic-practice component, and economicinstitutional component, and the data also have good validity with a standardised loading factor value of $\geq 0.50$.

Based on the findings in Figure 9, we have found a significant correlation between the Overall Cultural Component and Culture as a practical component (Chi-Square $=0.00$ ), also having a significant loading factor of 1.00 (higher than 0.5). However, there is no significant correlation between the Overall Cultural Component towards other components of value and institutional basis of culture. This finding shows that respondents' consumeristic behaviour is largely based on the frequency of a dish at home to meet the requirement of a nutritional diet. However, religious principles and familial customs may not lead to the behaviour of consumerism.

\section{The Social Dimension}

The second-order latent variable Social consists of three first-order variables: the value, practical, and institutional components, through the following measurement model. This represents the respondent's perception of the social components related to the value component in question no. S2 (about the selection of food to create an image of the family's socioeconomic status), and S24, S25, and S26 that the brand is the main consideration in buying rice, oil, and sugar. The variables represent the respondent's perception of the social components related to the practical component in questions no.
S8 (on the frequency of following the latest culinary information), S12 (on the frequency of watching culinary programs on TV), S13 (on the frequency of practising recipes obtained from culinary programs on TV), S15 (about the frequency of consumption of food products advertised on TV), S17 (about the frequency of using recipes from the social media), S19 (on the frequency of using recipes from friends) and S21 (on consuming food based on the advice of culinary figures). These variables represent the respondent's perception of the social components related to the institutional component, namely the influence of culinary programs on TV, social media, culinary figures, and friends to the activities of family consumption.

Figures 10, 11, and 12 describe the social influence of food on the respondents. Based on the findings above, there are no significant item in the questionnaire that determines the value and institutional component of the social dimension. The respondents appear not to provide an explicit consideration to purchase and consume food if it is solely based on the food brand or the influence of television culinary programmes. However, more importantly, it is the combination of all the components in the Social dimension that would determine consumerist behaviour. This will be further explained in the next section.

Based on the results of the output from the figures above, it shows that the indicator of the Goodness of Fit Index of the latent variables. The Root Mean Square of Error of Approximation shows the value of 0.00 (lower than 0.08), showing the model fits, and the Chi-square is not inflated due to a large sample (The model is saturated). It can be concluded

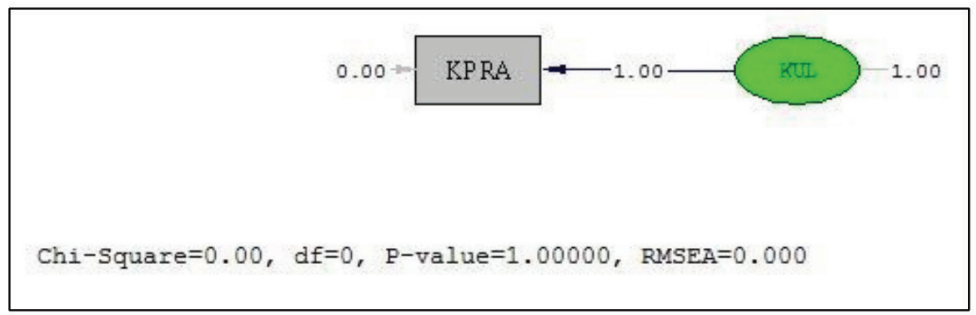

Figure 9: Data processing of the latent variable Cultural

(Second stage processing after eliminating items with standardised loading factor $<0.50$ ) 


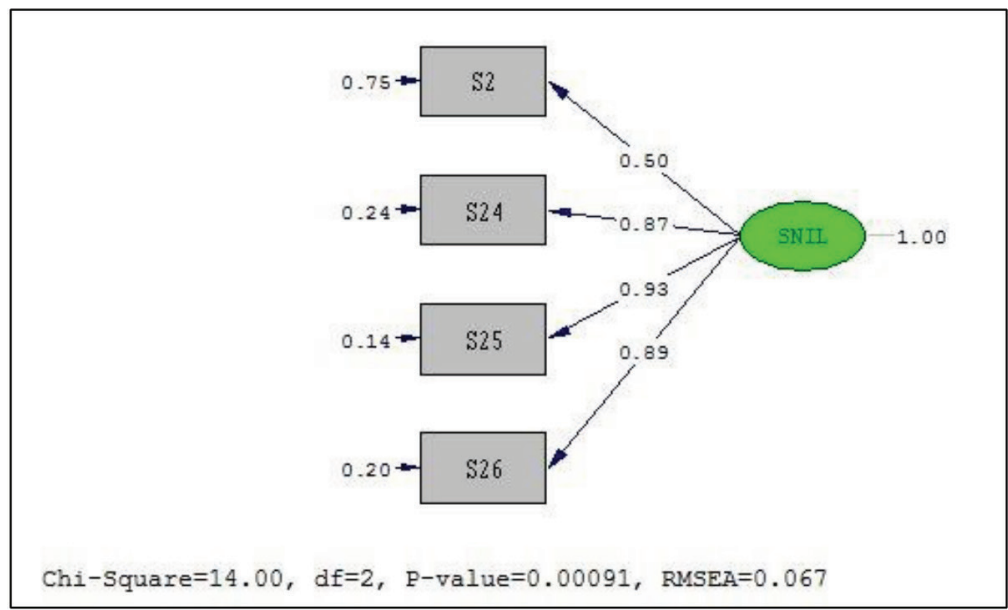

Figure 10: Data processing of the Value component of the latent variable Social (Second stage processing after eliminating items with standardised loading factor $<0.50$ )

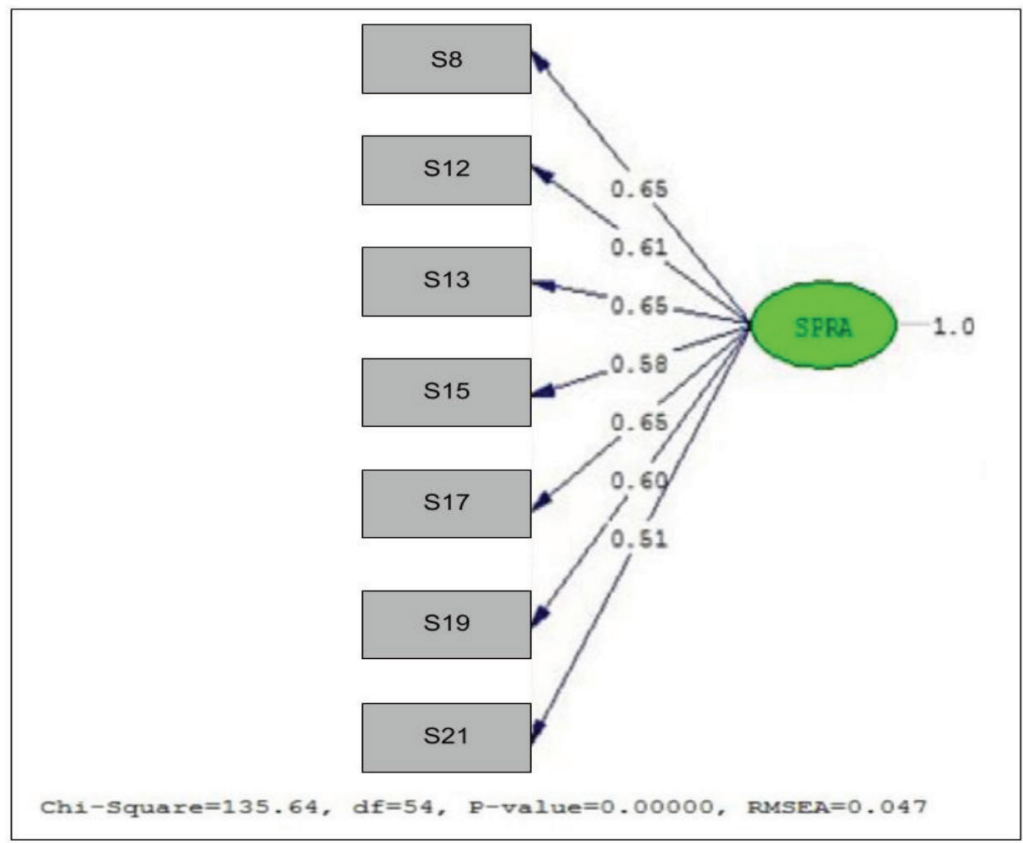

Figure 11: Data processing of the Practice component of the latent variable Social

(Second stage processing after eliminating items with standardised loading factor $<0.50$ )

that the data strongly support the model for latent variables economic-value component, economic-practice component, and economicinstitutional component, and the data also have good validity with a standardised loading factor value of $\geq 0.50$. The finding in Figure 13 shows that the overall Social component is significantly correlated to the value component, practice component, and institutional component, having a Chi-square value of 0.00 .

Among the three components, it is found that the institutional component has the strongest correlation towards the overall Social component, with a loading factor of 0.86 . It 


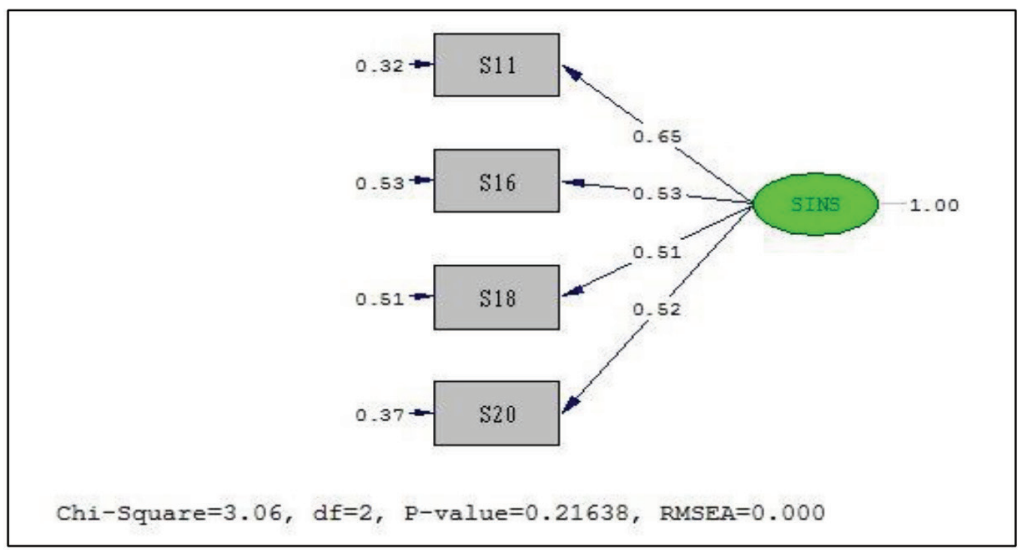

Figure 12: Data processing of the Institutional component of the latent variable Social (Second stage processing after eliminating items with standardised loading factor $<0.50$ )

is followed by the practice component with a loading factor of 0.76 , and the weakest correlation from the value component with a loading factor of 0.50. Although respondents consider every component as a part of their consumeristic behaviour, it is found that the institutional aspect has the highest tendency to determine consumerism. The elements that most influences the respondents' consumerist behaviour are the preference of culinary programmes on the television, social media, culinary figures, and friends towards the respondents' overall behaviour towards family food consumption. The second strongest influence is caused by the frequency of receiving culinary information, watching culinary programmes on recipes and food products on social media or television. The brand of basic food ingredients has the weakest influence; the respondents' knowledge of food ingredients does not determine their consumerist behaviour.

Based on the quantitative research findings in Figure 13, the structural equation model analysis demonstrates that both practical and institutional aspects of food consumption tends to point towards consumeristic behaviour among respondents in Bandung, an urban city of Indonesia. While the value aspect of consumerism, such as religion and traditional norms, might influence consumers' perception towards food consumption, they are not necessarily a determining aspect of consumerism. By putting the concept of

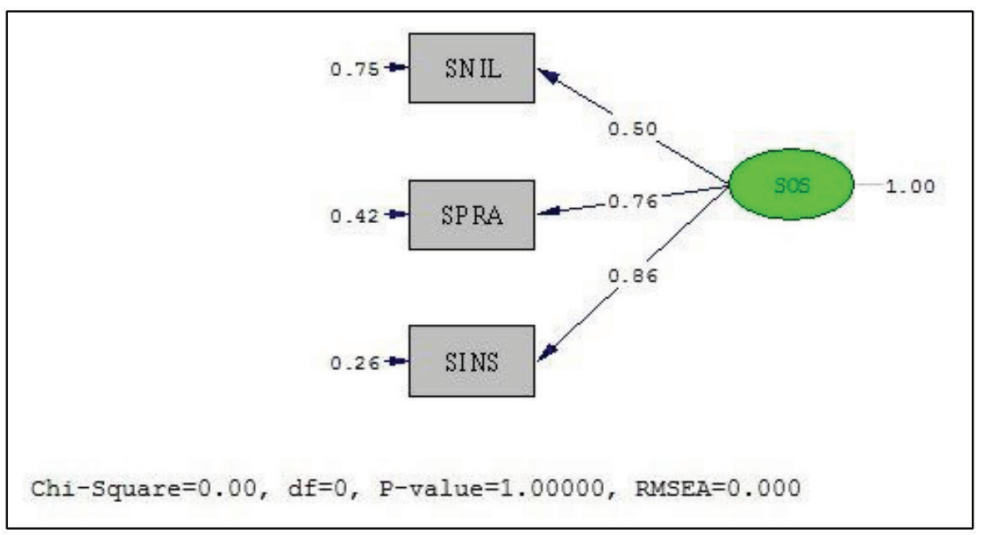

Figure 13: Data processing of the latent variable Social 
consumerism within the scope of an urban city in Indonesia (Bandung), this research shows that traditional norms (the cultural aspect) tend to be less relevant compared with the pragmatic need for everyday food consumption (the economic aspect), and the symbolic need for leisure consumerism (the social aspect).

By putting the dynamic of consumerism within the context of sustainable development, this research shows that an ideal sustainable socio-economic growth should comprise a balanced form of food consumption. The multidimensional aspect of food consumerism should not be neglected within the process of sustainable economic development. While the findings have shown that the practical and institutional aspect of food consumption tends to become the more domineering mode of consumeristic behaviour, it would be more ideal if food consumption is accompanied by elements of traditional and religious norms.

The process of food distribution for everyday need is necessarily a practical aspect of consumerism; there is less room for a sociological argument as it is crudely a pragmatic and economical distribution of goods. However, it appears that the process of leisure consumption through advertisement as an institutional aspect of consumerism tends to undermine the value aspect of traditional food consumerism. Leisure consumption of food, which tends to be distributed through advertisement, emphasises the global aspect of the economy. On the other hand, traditional food, which is emphasised by the value aspect of consumerism, is the domestic aspect of the economy.

In this study, the SEM analysis shows that the institutional aspect of leisure consumption is stronger in various areas of food consumption compared with the value aspect of traditional food consumption. In other words, the distribution of food that comes through the process of globalisation, such as western fast food, are better advertised, distributed, and stimulates the pattern of food consumerism within the urban city of Bandung. In contrast, the distribution of traditional food within the scope of the domestic economy tends to be undermined and become "less interesting" within the food market.

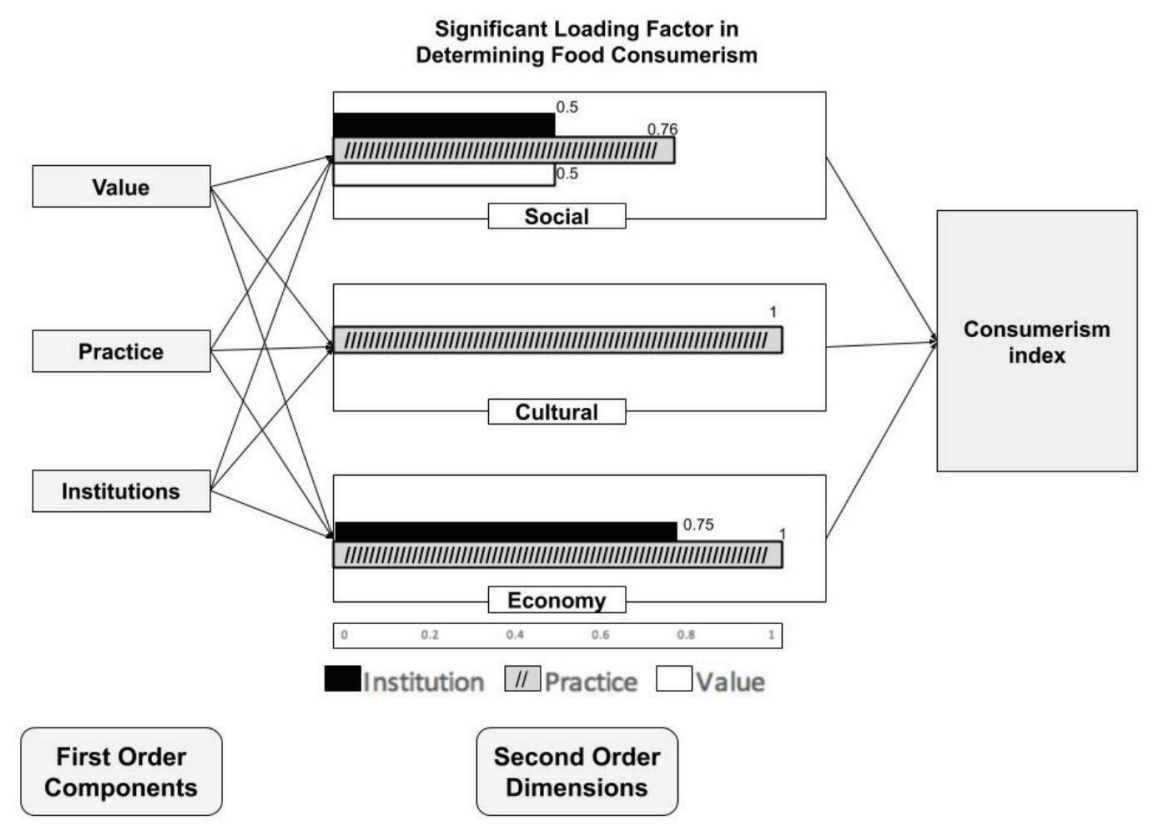

Figure 14: Research findings on the consumerism index 


\section{Conclusion}

This study focuses on consumerism as a pattern of consumption in the context of Sustainable Development. Consumerism can be understood by different dimensions: Economic, Cultural, and Social. The economic component is contextually related to price and the socioeconomic context of purchasing food, the cultural component is related to the religious or traditional preferences of consuming food, and the social component is related to the influence of social media, television, and peer groups towards consuming food. And within each dimension, there are different components that can further elaborate the respondents' consumerist behaviour: the value component (related to the cultural or religious principles in food consumption), the practical component (related to the frequency of food consumption), and the institutional component (related to the influence of social institutions, such as media, friends and restaurants towards food consumption).

The first-order analysis of components reflects the respondents' preference in food purchase or consumption; the second-order analysis of dimensions reflects the respondents' behaviour of consumerism. Based on the findings, the respondents' behaviour towards food consumption are affected by various dimensions. On the economic dimension, the respondents are driven based on the practical and institutional components that they are more likely to have an increase in food consumption through purchasing online food products and purchasing restaurant food products whenever a discount is made available. On the cultural dimension, the respondents only consider the practical component of food consumption the frequency of meals being served to meet nutritional diet; there is no strong correlation with religious or traditional preferences. On the social dimension, it is found that respondents consider the combined influence of food brand, and culinary programmes in media, which increases their consumerist behaviour. In all three dimensions of consumerism (economic, cultural, social), it is found that the practical component persists in determining consumerism.

The practical component is the basic component in measuring consumerism, cultural, and institutional components, which might also determine the respondents' consumerist behaviour to a certain level. In the economic and social dimension, both practical and institutional dimensions are very important elements to be considered. The respondents' consumerist behaviour is influenced by social components through media and advertisements. Consumerism increases as more options for food products and advertisements are made available through the television, internet, and peers. At the same time, although food prices, traditional and religious principles are considered in food selection, they do not determine the respondents' consumerist behaviour.

The gap between the institutional and value aspect of food consumption, the difference between the consumption of food from the global and local sources, will perhaps be the key determinant of sustainable development. A sustainable form of food consumption should maintain a balance between global and local consumption of food. This research shows that there is a greater tendency among domestic respondents to consume food from external global sources compared with consuming food from the internal domestic source. Further studies on the empowering of domestic food and value aspect of traditional food consumption are recommended, particularly in relation of globalisation and sustainable economic development.

Within the context of sustainable development, a multidimensional analysis of food consumption remains novel, relevant, and crucial. Sustainability is the balance of production and consumption within the scope of long-term development. A sustainable form of consumption, in this research, involves the dynamic of economic, social, and cultural dimensions, which interplays, drives and sustains the robustness of food production and consumption relation. Food consumption based 
on economic reality alone does provide a numeric value in the exchange process. However, it is the social and cultural aspect that motivates and lubricates the economical mechanics, drives, sustains and even further develop the growth of the market and consumers' interests. Therefore, the incorporation of traditional food and its values, and the involvement of social interactions in the flow of food consumption are crucial elements that balance and contribute to economic growth. The novelty of the triadic elements of consumption (social, cultural, economic) has been applied in this research, and is recommended for future applications and studies.

\section{Acknowledgements}

This study was supported by DRPM (Research Directory and Community Services) University of Indonesia for Research Programme of KEMENRISTEKDIKTI 2015-2016, having the research grant number: 0486/UN2.R12/ HKP.05.00/2015.

\section{References}

Ageev, Ilya, A., \& Ageeva, Vera,V. (2015). Urban lifestyle as an element of consumption ideal and economic wellbeing: Meaningchanging transformation from soviet period to modernity. Procedia Social Behavioural Science, 166, 24-29.

Amin, Ash. (1994). Post-fordism: A reader. Oxford: Blackwell. Assadourian, Erik. (2010). Transforming cultures: From consumerism to sustainability. Journal of Macromarketing, 30(20), 186-191.

Astuti, Sri, \& Hanan, Himasari. (2012). The behaviour of consumer society in consuming food restaurants and cafes. Procedia Social Behavioural Science, 42, 429-435.

Barbopoulos, Isak, \& Johansson, Lars-Olof. (2016). A multi-dimensional approach to consumer motivation: Exploring economic, hedonic, and normative consumption goals.
Journal of Consumer Marketing, 33(1), 7584.

Bashir, Abdul, \& Yuliana, Saadah. (2018). Identifying factors influencing rice production and consumption in Indonesia. Jurnal Ekonomi Pembangunan: Masalah Ekonomi dan Pembangunan, 19(2), 172185.

Bauman, Zygmunt. (2005). Work, consumerism, and the new poor. Open University Press.

Bergman, Tabe. (2018). American television: Manufacturing consumerism. In PedroCaranana, Joan, Broudy, Daniel \& Klaehn, Jeffery (Eds.), The propaganda model today: Filtering perception and awareness. (pp. 159-172). London: University of Westminster Press.

Bossy, Sophie. (2014). The utopias of political consumerism: The search of alternatives to mass consumption. Journal of Consumer Culture, 14(2), 179-198.

Brown, Halina Szejnwald \& Vergragt, Philip, J. (2015). From consumerism to wellbeing: Toward a cultural transition? Journal of Cleaner Production, 1-10.

Chen, A., Lu, Y., \& Gupta, S. (2017). Enhancing the decision quality through learning from social commerce components. Journal of Global Information Management, 25(1), 66-91.

Dalgliesh, Bregham. (2014). Zygmunt Bauman and the consumption of ethics by the ethics of consumerism. Theory, Culture \& Society, 31(4), 97-118.

Dinh, Trang Thi-Huyen, Vo, Duc Hong, Vo, Anh The, Nguyen \& Thang Cong. (2019). Foreign direct investment and economic growth in the short run and long run: Empirical evidence from developing countries. Journal of Risk Financial Management, 12(176), 1-11.

Eryandra, Alvin, Sjabadhyni, Bertina \& Mustika, Martina Dwi. (2018). How older consumers' perceived ethicality influences brand loyalty. SAGE Open, 8(2), 1-5. 
Firat, Aytekin, Kutucuoglu Yuce, Kemal, Saltik, Isil Arikan, \& Tuncel Ozgur. (2013). Consumption, consumer culture and consumer society. Journal of Community Positive Practices, 8(1), 182-203.

Gill, Rosalind \& Pratt, Andy. (2008). "in the social factory? Immaterial labour, precariousness and cultural work". Theory, Culture \& Society, 25(7-8), 1-30.

Huang, A., Dawes, J., Lockshin, L., \& Greenacre, L. (2017). Consumer response to price changes in higher-priced brands. Journal of Retailing Consumer Services, $39,1-10$.

Ikran, Eym. (2009). A study on islamic consumerism from a cultural perspective: Intensification of muslim identity and its impact on the emerging muslim market. International Area Studies Review, 12(2), 3-19.

Jain, Sankalp. (2016). Globalization and its impact on consumer culture and competition policy.

Jati, Kumara. (2013). Sugar price analysis in Indonesia. International Journal of Science and Humanity, 3(4), 369-374.

Jha, Praveen \& Chakraborty, Amit. (2018). Postfordism, global production networks and implications for labour: Some case studies from national capital region, India. Institute for Studies in Industrial Development.

Klarin, Tomislav. (2018). The concept of sustainable development: From its beginning to the contemporary issues. Zagreb International Review for Economics and Business, 21(1), 67-94.

Kocakaya, Serhat, \& Kocakaya, Ferit. (2014). A structural equation modeling on factors of how experienced teachers affect the students' science and mathematics achievements. Education Research International.

Kurenlahti, Mikko \& Salonen, Arto. (2018). Rethinking consumerism from the perspective of religion. Sustainability, 10(7), 2454.
Kurniawan, Robi, \& Managi, Shunsuke., (2018). Economic growth and sustainable development in Indonesia: An assessment. Bulletin of Indonesian Economic Studies, 54(3), 339-361.

Lazzarato, Maurizio. (2004). From capitallabour to capital-life. Transl. V. Fournier et al. Ephemera, 4(3), 187-208.

Lazzarato, Maurizio. (2007). Strategies of the political entrepreneur. SubStance \#112, 36(1), 87-97.

Lazzarato, M. (2009). Neoliberalism in action: Inequality, insecurity and the reconstitution of the social. Theory, Culture and Society, 26(6), 109-133.

LPPM IPB. (2018). Market study on food sector in Indonesia. International Center for Applied Finance and Economics. Lembaga Penelitian Pengabdian Masyarakat Instittut Pertanian Bogor.

Migone, Andrea. (2007). Hedonistic consumerism: Patterns of consumption in contemporary capitalism. Review of Radical Political Economics, 39(2), 173-200.

Nicolaou, M., Doak, C. M., Dam, R. M. V., Brug, J., Stronks, K., \& Seidell, J. C. (2009). Cultural and social influences on food consumption in Dutch Residents of Turkish and Moroccan Origin: A qualitative study. Journal of Nutrition Education and Behaviour, 41(4), 232-241.

O'Cass, Aron, \& Emily McEwen. (2004). Exploring consumer status and conspicuous consumption. Journal of Consumer Behaviour, 4(1), 25-39.

Otero, Juana Camacho, Boks, Casper, \& Pettersen, Ida Nilstad. (2018). Consumption in the circular economy: A literature review. Sustainability, 10, 2758: 1-25.

Prayudi, Probosari, N., \& Ardhanariswari, K. A. (2018). Analysis of the development of Bandung as creative city. International Journal of Scientific \& Engineering Research, 8(9), 1025-1030. 
Rahadi, A., Alamanda, D. T., \& Pancawuri, Y. (2017). Mapping of traditional marketplaces in Bandung, Indonesia: Preserving the local culture, identity \& heritage. Journal of Humanities, Language, Culture and Business, 1(3), 108-120.

Rukmana, Deden. (2008). The growth of Jakarta metropolitan area and the sustainability of development in Indonesia. International Journal of Environmental, 4(1), 99-106.

Robinson, William. (2011). Global capitalism theory and the emergence of transnational elites. Critical Sociology, 38(2), 349-363.

Rohani, A., \& Nazari, M. (2012). Impact of dynamic pricing strategies on consumer behaviour. Journal of Management Research, 4(4), 143-159.

Sarstedt, Marko, Ringle, Christian \& Hair, Joseph. (2017). Partial Least Squares Structural Equation Modeling. Handbook of Market Research, 1-40.

Sebastian, Lea \& Bauler, Tom. (2013). Use and influence of composite indicators for sustainable development at the EU-Level. Ecological Indicators, 35, 3-12.

Seda, Francisia, \& Setyawati, Lugina. (2013). Consumerism indicator construction: A portrait of household food consumption patterns in Jakarta, Indonesia. Journal of Economics and Sustainable Development, 4(19), 160-174.

Shukla, Paurav. (2010). Status consumption in cross-national context: Sociopsychological, brand and situational antecedents. International Marketing Review, 27(1), 108-129.

Simmie, James \& Martin Ron. (2010). The economic resilience of regions: Towards an evolutionary approach. Cambridge Journal of Regions, Economy and Society, 1-17.
Stellarosa, Yolanda \& Ikhsano, Andre. (2015). Media and the shaping of consumer society in Jakarta. Procedia Social and Behavioural Science, 407-410.

Taiss, Aaron. (2012). Contextualizing the current crisis: Post-fordism, neoliebral restructuring, and financialization. Colombia Internacional 76, julio a diciembre de, 2012, 51-79.

Trentmann, Frank. (2004). Beyond consumerism: New historical perspectives on consumption. Journal of Contemporary History, 39(3), 373-401.

Virno, Paolo. (2007). "Post-fordist semblance". SubStance \#112., 36(1), 42-46.

United Nations. (2015). Economic and social survey of Asia and the Pacific 2015. United Nations Publication.

Victor, V., Thoppan, J. V., Nathan, R. J., \& Maria, F. F. (2018). Factors influencing consumer behaviour and prospective purchase decisions in a dynamic pricing environment - An exploratory factor analysis approach. Social Sciences, 7(153), 1-14.

Wahyudi, A., Kuwornu, J. K. M, Gunawan, E., Datta, E., \& Nguyen, L. T. (2019). Factors influencing the frequency of consumers' purchases of locally-produced rice in Indonesia: A poisson regression analysis. Agriculture, 9, 117, 1-17.

Wang, Huifen, Luo Guoliang, \& Hong, Huanping. (2016). Beyond sociomateriality and sense-making: Planting symbolic power and critical realism into strategy-as-practice logic. Open Journal of Business and Management, 4(2), 1-11.

Xavier, Marlon. (2016). Subjectivity under consumerism: The totalization of the subject as a commodity. Psicologia \& Sociedade, 28(2), 207-216. 